\title{
Managerial Competencies Required to Achieve Sustainable Development Projects: A Proposed Model for Managers
}

\author{
Afaf Hassan \\ Department of Environmental Health and Safety, Abu Dhabi University \\ PO Box 59911, Abu Dhabi, United Arab Emirates
}

Tel: 971-2501-5555Ｅ-mail: afaf.h-adjunct@adu.ac.ae

\author{
Received: January 10, 2020 Accepted: February 2, 2020 Published: August 30, 2020 \\ doi:10.5296/emsd.v9i3.17603 URL: https://doi.org/10.5296/emsd.v9i3.17603
}

\begin{abstract}
This study deals with the managerial competencies of current managers that are required to achieve sustainable development projects. A comparative literature review is conducted to summarize the critical managerial competencies in general. Then, this is narrowed down to find the managerial competencies that lead to the proper accomplishment of sustainable development projects. Considering these views, the purpose of this exploration is to discover the significance of managerial competencies on the achievement of sustainable development projects. The findings indicate that communication, leadership, development orientation, achievement orientation, motivation, teamwork, innovation, and decision making are the most critical managerial competencies that can enhance the performance of managers towards achieving sustainable development projects. Thus, this article demonstrates a model inclusively for managers to link the found managerial competencies with the realization of sustainable development projects. The model is focused mainly on the specific managerial competencies that will encourage managers to perform outstanding results in recent as well as future sustainable development projects.
\end{abstract}

Keywords: Managerial competencies, Sustainable development, Sustainable projects

\section{Introduction}

Competencies are desired attitudes, knowledge, skills, and underlying characteristics or behavior, which differentiate high performers from average ones (Boyatzis 1982). Competencies also explain what individuals are able to do and why they decide to act in a specific way (Liikamaa, 2015). However, there various are types of competencies such as 
professional competencies, managerial competencies, job-task competencies, behavioral competencies, and entrepreneurial competencies (Ahsan, Ho \& Khan, 2013; Chong, 2013; Isidro-Filho et. al, 2013; Lampel, 2001). In this study, the focus is on managerial competencies. Managerial competencies are defined as characteristics that are related to superior job performance, given that an individual's performance is evaluated in terms of particular actions or behavioral signs (Boyatzis, 1982; Chong, 2013). At early stages, managerial competencies have been grouped into two categories that are (1) consummate competencies: they cover productivity, conceptualization, efficiency orientation, impact, diagnostic use of concepts, self-confidence, oral presentations, processes management, power, and objectivity. (2) threshold competencies: they involve knowledge, self-control, authority, energy, adaptability, self-assessment, logical thinking, spontaneity, and developing others (Boyatzis, 1982). Henceforth, scholars have provided different classifications for managerial competencies such as communication, leadership, development orientation, flexibility, influence, motivation, teamwork, achievement orientation, quality focus, customer focus, planning, innovation, and decision-making competencies (Abraham et al., 2001; Arditi et al., 2013; Chong, 2013; Cockerill et al., 1995; Fanelli et al., 2020; Fulop, 2012; Raišiené, 2014; Wadongo et al., 2011; Watson et al., 2004; Wickramasinghe \& De Zoyza, 2011).

Sustainable development projects are concerned about meeting the needs of the present without compromising the needs of future, in a way that maintains economic growth, social equity, and environment protection (Ciegis et al., 2011; Dumitrescu, et al., 2014; Meng \& Li, 2001). Sustainable development has emerged as an international issue that addresses environmental debates in a developmental context. "Still, a shared focus on economic, environmental, and social goals is a hallmark of sustainable development and represents a broad consensus on which the world can build" (Sachs, 2012, p. 2206). This means that it is important to understand that poverty is the result of environmental destruction to achieve economic development and equity (Ciegis et al., 2011; Fukuda-Parr \& Muchhala, 2020). Accordingly, the goals of economic, social, and environmental sustainability need to be integrated into a sustainable development strategy, but with a novel model that involves concerns for economic growth, social inclusion, and the environmental protection (Ciegis et al., 2011; Fukuda-Parr \& Muchhala, 2020; Meng \& Li, 2001).

Managerial competencies can be used to attain the desired sustainable development outputs (Chung et al., 2016; Dudin et al., 2017; Dumitrescu, et al., 2014; Dzhengiz \& Niesten, 2019; Mukhopadhyay et al., 2011; Remington-Doucette \& Musgrove, 2015). This indicates that having a manager with robust managerial competencies is essential to complete sustainable development projects. The reason is that such competencies allow managers to understand the complexity of different systems, explore future options, craft sustainability visions, and develop credible strategies (Wiek et al., 2011). Besides, effective managerial competencies that are directed towards achieving sustainable projects allow managers to recognize the value of knowledge (Dzhengiz \& Niesten, 2019); realize business objective (Bruwer et al., 2018); encourage staff development (Dudin et al., 2017); keep learning from current and previous projects (Dzhengiz \& Niesten, 2019); support socio-economic development (Dudin et al., 2017); secure sustainable development practices (Bruwer et al., 2018), solve real-world 
problems (Remington-Doucette and Musgrove, 2015); develop innovative practices (Chung et al., 2016); and become committed to reaching better quality of social, environmental, and economic outcomes (Dzhengiz \& Niesten, 2019). Wiek, Withycombe, and Redman (2011) have added that managers with desired managerial competencies have a higher probability to make decisions about what should or should not be done, and under what circumstances, in sustainable development projects.

Thus, this paper is focused on exploring the previous literature about managerial competencies and sustainable development. It also has examined the existence of a relationship between managers' managerial competencies and the completion of sustainable development projects. Lastly, the study proposed a model of managers' managerial competencies that are essential to achieve sustainable development projects.

\subsection{Rationale of the Study}

Nowadays, sustainable development has become a necessity to cope with the current requirements of a better economy, society, and environment (Ciegis et al., 2011; Secundo et al., 2020; Sobol, 2008; Wiek et al., 2011). Thus, for sustainable development to be achieved accurately in projects, the demand for managers who acquire robust managerial competencies is increasing (Arditi et al., 2013; Boyatzis, 1982; Bucur, 2013; Chong, 2013; Dumitrescu, et al., 2014; Fanelli et al., 2020; McGregor \& Tweed, 2001; Shaikh et al., 2017; Wadongo et al., 2011; Wickramasinghe \& De Zoyza, 2011). In other words, such competencies can enhance the overall performance of managers in accomplishing sustainable projects. For example, managers with appropriate managerial competencies (such as communication, leadership, development orientation, achievement orientation, motivation, teamwork, innovation, and decision-making) have higher potential to deliver sustainable development projects (Bruwer et al., 2018; Chung et al., 2016; Dudin et al., 2017; Dumitrescu, et al., 2014; Dzhengiz \& Niesten, 2019; Fulop, 2012; Mukhopadhyay et al., 2011; Remington-Doucette \& Musgrove, 2015; Sil \& Banerjea, 2011; Wiek et al., 2011). Here, it is critical to highlight that sustainable development projects cover economic viability, social inclusion, and environmental protection (Chung et al., 2016; Dzhengiz \& Niesten, 2019; Fulop, 2012; Wiek et al., 2011). Whereas, a manager who lacks these competencies might face difficulties in communicating with stakeholders, solving problems, resolving team conflicts, dealing with technologies, or making appreciate decisions (Arditi et al., 2013; Boyatzis, 1982; Chong, 2013). Therefore, this study has proposed a model that demonstrates managers' managerial competencies that are required to achieve sustainable development projects effectively.

\subsection{Methodology}

This is exploratory research based on prior literature related to the topic of the study as managerial competencies and sustainable development in projects. The literature was reviewed systematically. This research has developed the subject based information and knowledge. It has also emphasized the aspect of managerial competencies that can support and enhance the completion of sustainable development projects. Hence, the study has described some terms related to the subject matter and proposed a model for managers, who acquire effective managerial competencies, to accomplish sustainable development projects 
based on the reviewed literature. The researcher has found some articles related to this study and those were selected randomly to satisfy the purpose of the research.

\section{Literature Review}

\subsection{Managerial Competencies}

In general, competencies have been described as a combination of effective characteristics, behaviors, skills, and knowledge that can be developed when gaining more experience and training at workplace (Long \& Ismail, 2011). More specifically, Boyatzis (1982) has stated that managerial competencies are the characteristics of an individual that lead to superior job performance. Yet, "[t]here is a great consensus that managerial competencies are linked in a complex way to managerial performance, being the main requirements for consistent performance over time" (Bucur, 2013, p. 365). This emphasizes the point that managerial competencies are not only utilized as measures for performance but also studying and analyzing them is significant to improve projects' performance (Bucur, 2013). In 1994, managerial competencies have included strategic positioning, acquiring financing, getting raw materials, designing an organizational structure, creating financial controlling system, determining information system, employing personnel management, administering material welfare, forming social activities involving employees and families, offering developmental activities for employees, encouraging mass participation, supporting the larger community, marketing decisions, planning long-term development, controlling inventory, scheduling production, promoting technical innovation, managing production process, arbitrating interpersonal and interdepartmental conflicts, and negotiating with government agencies about profit sharing and state subsidy (Bu, 1994). Managerial competencies also cover information search, conceptual flexibility interpersonal search, managing interaction, developmental orientation, impact, self-confidence, presentation, and achievement orientation (Cockerill et al., 1995). Later, Longest (1998) has stated that managerial competencies include technical managerial, interpersonal, political competencies, commercial competencies, and governance competencies. Whereas, Watson, McCracken, and Hughes (2004) have classified managerial competencies into seven main categories that are general management, people management, self-management, operational, business competencies, technical competencies, and personal competencies. This implies that managerial competencies might vary depending on the situation, but the common point is that they add value to the managers' achievements. In 2011, authors have introduced a wider range of managerial competencies (Abraham et al., 2001; McGregor \& Tweed, 2001; Wadongo et al., 2011; Wickramasinghe \& De Zoyza, 2011). For instance, Abraham, Karns, Shaw, and Mena (2001) have pointed out that successful managers acquire key managerial competencies such as good communication skills, problem-solving, result orientation, interpersonal skills, leadership skills, customer focus, flexibility, adaptability, teamwork, dependency, trustworthiness, quality-focused, technical expertise, business expertise, hard work, staff development, safety development, safety-conscious, imagination, risk-taking, time management, purposeful, professional dress, uncompromising, proficiency in a foreign language, previous foreign experience, and innovation. McGregor and Tweed (2001) have clarified that managers with adequate managerial competencies would be able to see the big picture, recognize the skills of others, 
identify problems, maintain open communication, motivate themselves, identify customer needs, generate ideas, lead, manage budgets, and manage costs. Wickramasinghe and De Zoyza (2011) have elaborated that managerial competencies entail a wide range of categories such as customer relations knowledge, cost consciousness, change handling skills, strategizing ability, technology application skills, empathy with people, conflict resolution, empowerment ability, holistic, creativity, coaching ability, safety focus, learning, flexibility, listening, negotiation, learning, ethical, risk-taking, quality focus, team player, time management ability, customer focus, pressure management skills, attitude to meet targets, oral communication, written communication, planning, scheduling, achievement-oriented, and positive vision. While, Wadongo, Kambona, and Odhuno (2011) have mentioned that understanding self and others, managing conflict, reducing information overload, analyzing information critically, presenting information, living with change, managing change, building and maintaining a power base, negotiating agreements, developing subordinates, managing time and stress, participative decision making, team building, technical competence, and motivating others are critical examples of managerial competencies. Arditi, Gluch, and Holmdahl (2013) have provided a wider range of managerial competencies that are achievement, planning, oral communication, initiative, sensitivity, resilience, customer focus, flexibility, adaptability, teamwork, quality focus, risk-taker, innovation, analytical thinking, decision making, relationships, business awareness, learning orientation, authority, presence, motivating others, and developing people. Moreover, managerial competencies have also been categorized as strategic perspective; analysis and judgment; planning and organizing; managing staff; persuasiveness; assertiveness and decisiveness; oral communication; energy and initiative; creativity and sensitivity; adaptability and resilience; distinct competencies; business sense and integrity; achievement motivation; reading and written communication; and problem analysis and decisiveness (Chong, 2013). In the same period, Bucur (2013) has verified that managerial competencies cover influence and collaboration, strategic thinking, results orientation, team leadership, transformational leadership, and learning. Later, Raišienė (2014) has specified that managerial competencies comprise the ability to communicate, make decisions in a team, collaborate, help the employees achieve results, and overcome various contradictions. Although there are several managerial competencies, scholars have continued to add more categories (Shaikh et al. 2017; Fanelli et al., 2020). For instance, managerial competencies such as conceptual skills, personal image, personal value, experience, work effectiveness, awareness of (emotional and physical) barriers, career awareness, incentives, and networks help managers achieve their sustainable development targets (Shaikh et al. 2017). Recently, Managerial competencies have been classified into seven categories that are leadership, costing, analysis, communication, human resources management, organizational design, programming, and quality (Fanelli et al., 2020). Though, it is crucial to realize that lacking the needed managerial competencies weakens managers' as well as project teams' competition and efforts to secure projects (Long, Ismail \& Amin, 2013).

\subsection{Sustainable Development Projects}

Nowadays, sustainable development does not have significant attention; thus, sustainable 
development definition, priorities, evaluations, changes, and perspectives are not well developed (Ciegis et al., 2011). However, sustainable development as the perception evolved has referred to "people-centered development and ending poverty and distributional equity as key objectives; structural transformation of national economies and reforms in global economic governance to create an enabling environment for development" (Fukuda-Parr \& Muchhala, 2020, p.104706). Here, it is worthwhile to keep in mind that although the definitions of sustainable development vary, nearly all of the world's societies admit that they target a combination of environmental protection, economic growth, and social inclusion, as the definite goals change internationally, among and within societies (Sachs, 2012). Hence, for sustainable development projects to be achieved successfully, there should be an advancement in three main spheres that are economic, social, and environmental (Ciegis et al., 2011). Secundo, Ndou, Vecchio, and De Pascale (2020) have pointed out that sustainable development framework embraces a wide variety economic, social and environmental issues, involving energy, climate change, biodiversity, gender, equality, peace, security, healthcare, education, food supply, economic growth and sustainable consumption and production. They have added that the main goal of sustainable development projects is to find effective solutions for complex challenges such as climate change, energy, pollution, ecosystem resilience, migration, food security, and many other issues that require a cross-disciplinary perspective (Secundo et al., 2020). However, sustainable development projects are projects that are aimed to encourage current generations to meets their needs without compromising the ability of future generations to meet their needs as well (Remington-Doucette and Musgrove, 2015). Sustainable development projects also involve appropriate responses to existing and anticipated problems such as desertification, climate change, pandemics, poverty, a war that are, in common, featuring high degrees of urgency, complexity, and damage potential (Wiek, Withycombe, \& Redman, 2011). Sustainable development projects should result in the creation of partnership and dialogue between local governments and their communities. At the same time, it is critical to understand that local governance is crucial for sustainable development. If managers and project team members are motivated to perform as key actors in local development, they feel responsible for the directions and visions of development set in local laws, policies, and regulations. A society's wellbeing relies on assuring that all its individuals feel that they have a stake in it. The association between local society and government can enhance or sometimes obstruct sustainable development initiatives. The change towards sustainable development in projects requires more transparent decision-making procedures that encourage participation by a wide range of stakeholders (Sobol, 2008). Yet, the success of sustainable development projects requires managers with robust managerial competencies, which in turn can allow them to overcome obstacles and move forward towards sustainable development (economic, social, and environmental) targets.

\subsection{Managerial Competencies and Sustainable Development Projects}

Sustainable development projects stress the importance of social, economic, and environmental responsibility (Ciegis et al., 2011; Fukuda-Parr \& Muchhala, 2020; Remington-Doucette \& Musgrove, 2015; Secundo et al., 2020). In turn, this can become 
credible when in charge managers devote talent, resources, and time to local or international projects without the prospect of waiting for an immediate return (Fulop, 2012). This indicates that acquiring proper managerial competencies can increase managers' chance to complete sustainable development projects appropriately. In support of this, Liikamaa (2015) has emphasized that obtaining effective managerial competencies enhances managers' opportunities to overcome the daily challenges associated with sustainable development projects. Lambrechts et al. (2013) have added that managers working for sustainable development project should have robust managerial competences. The reason is that these competencies encourage managers to take responsibility for their work, respect the emotions of others, work with a clear vision, think using a future oriented perception, become dedicated for sustainable development, and act decisively (Lambrechts et al., 2013). Hence, this study has focused on managers' managerial competencies that have a strong influence on completing sustainable development projects successfully.

\subsubsection{Communication}

One of the core managerial competencies that are critical to achieving sustainable development is communication competency (Bruwer et al., 2018; Dumitrescu, et al., 2014; Dzhengiz \& Niesten, 2019; Fulop, 2012; Lambrechts et al., 2013; Mukhopadhyay et al., 2011; Remington-Doucette \& Musgrove, 2015; Wiek et al., 2011). Communication competencies can be described as persuasive communication, as the manager used them to convene project team members and other stakeholders about the importance of introducing and using more sustainable development technologies (Mukhopadhyay et al., 2011). Besides, communication competencies are considered to be fundamental to the delivery of sustainable development projects (Wiek et al., 2011). Several studies have supported this relationship (Bruwer et al., 2018; Dzhengiz \& Niesten, 2019; Mukhopadhyay et al., 2011; Remington-Doucette \& Musgrove, 2015; Wiek et al., 2011). In clarification, Wiek, Withycombe, and Redman (2011) have emphasized the point that communication skills are important for sustainability professions, as advanced skills in communicating leads to improvements in sustainability research and problem-solving techniques (Wiek et al., 2011). This indicates that communication competencies are essential for managers to present information and solve problems that are effectively related to sustainable development. Remington-Doucette and Musgrove (2015) have mentioned that advanced communication enables collaboration among diverse stakeholders, specifically about sustainability goals and requirements (Remington-Doucette \& Musgrove, 2015). Here, it is crucial to realize that effective communication with stakeholders is a major managerial concern that can facilitate the achievement of sustainable development projects. Furthermore, Bruwer, Coetzee, and Meiring (2018) have pointed out that experience managers have strong communication skills that allow them to solve problems. The reason is that the processes and technologies, used to attain sustainable development, are new and could have many problems especially when used for the first time. This makes the ability to solve problems through effective communication essential. Lately, it has been argued that responsible managers can communicate about different issues such as introducing technologies that aim to reduce environmental harm and sharing various ideas about sustainability among team members, in turn, this will allow them 
to adopt sustainable development innovations (Dzhengiz \& Niesten, 2019). This signifies that one of the major responsibilities of managers is to keep developing their communication competencies, to cope with the new requirements of the emerging sustainable development projects. Accordingly, there is a positive relationship between a manager's communication competency and the achievement of sustainable development projects.

\subsubsection{Leadership}

Many studies have highlighted the association between leadership competency and sustainable development projects (Bruwer et al., 2018; Dumitrescu, et al., 2014; Dzhengiz \& Niesten, 2019; Fulop, 2012; Lambrechts et al., 2013; Liikamaa, 2015; Mukhopadhyay, Sil \& Banerjea, 2011; Wiek et al., 2011). Leadership competencies are fundamental expertise which managers should possess to achieve sustainable development projects (Bruwer et al., 2018; Dzhengiz \& Niesten, 2019; Mukhopadhyay et al., 2011). In other words, a manager who does not have real leadership skills might not be able to deliver sustainable development projects. This is due to many reasons, for instance, managers' leadership methods can have an impact on the sustainable behavior of team members and the extent to which they engage in eco-friendly practices (Dzhengiz \& Niesten, 2019). Good leadership competencies also help in building and controlling a robust team that works effectively towards achieving sustainable development. Additionally, leadership is the key to overcome all challenges that could be linked to ecological sustainability (Dzhengiz \& Niesten, 2019). The reason is that environmental leaders are considered to be driving forces in motivating project team members to adapt to changes and be responsible for social and environmental issues (Dzhengiz \& Niesten, 2019). Wiek, Withycombe, and Redman (2011) have added that solving sustainable development problems and generating new opportunities require successful negotiations among community leaders, entrepreneurs, scientists, politicians, and many more. Other studies have emphasized that managers' leadership competencies play a vital rule in the realization of sustainable development projects (Bruwer et al., 2018; Dzhengiz \& Niesten, 2019; Remington-Doucette \& Musgrove, 2015; Wiek et al., 2011). In justification, sustainable development leadership has been shown to enhance creative processes of problem-solving (Dzhengiz \& Niesten, 2019), urge collaboration among projects' stakeholders (Wiek et al., 2011), address real-world sustainability problems (Remington-Doucette \& Musgrove, 2015), and have better control over all stages of sustainable projects (Bruwer, Coetzee \& Meiring, 2018). In brief, mangers can motivate, facilitate, and solve problems using well-developed leadership skills, which increase the potential of managing sustainable development projects accurately (Remington-Doucette \& Musgrove, 2015). Thus, it is essential to enhance the leadership competencies of current managers as this will allow them to develop a thorough understanding and appreciation of the varied perspectives involved in addressing the challenges of sustainable development (Remington-Doucette \& Musgrove, 2015). Considering these findings, there is a positive relationship between a manager's leadership competency and the achievement of sustainable development projects. 


\subsubsection{Developmental Orientation}

Studies have supported the existence of a relationship between managers who acquire "developmental orientation" competency and the successful completion of sustainable development projects (Dudin et al., 2017; Dzhengiz \& Niesten, 2019; Fulop, 2012; Lambrechts et al., 2013; Mukhopadhyay et al., 2011; Wiek et al., 2011). But authors had different viewpoints about being a development-oriented manager in the field of sustainable development (Dudin et al., 2017; Dzhengiz \& Niesten, 2019; Mukhopadhyay et al., 2011; Wiek et al., 2011). In clarification, development orientation competencies of managers make them highly concerned about developing new techniques that measure human performance (Mukhopadhyay et al., 2011), enhancing career development through training and better compensations (Mukhopadhyay et al., 2011), improving processes (Mukhopadhyay et al., 2011), acquiring more knowledge about the environment (Dzhengiz \& Niesten, 2019), being able to find a solution for complex real-world problems (Dzhengiz \& Niesten, 2019), and having the ability to adapt to sudden changes through solving the particular challenges of sustainable production (Dzhengiz \& Niesten, 2019). Additionally, scholars have highlighted different views about the aspect of developmental orientation, particularly when dealing with sustainable development projects (Dudin et al., 2017; Dzhengiz \& Niesten, 2019; Mukhopadhyay et al., 2011; Wiek et al., 2011). For example, Dzhengiz and Niesten (2019) have stated that managers should develop their environmental capabilities, critical thinking, ethical values, formal knowledge, and soft skills that allow them to perform better in sustainable projects. They have also added that some of the key actions towards sustainable development are improving projects' environmental strategy, innovating, and encouraging stakeholders to report deficiencies of resources or technologies used (Dzhengiz \& Niesten, 2019). Development can go beyond that to cover the advancements of human, environmental, technology, and business resources in a way that improves projects' performance and conserves the environment (Dzhengiz \& Niesten, 2019). Development can also incorporate establishing a change in activities, practices, and routines to meet sustainable development goals (Dzhengiz \& Niesten, 2019). This implies that managers, who are fully directed toward the development of their projects, have a higher opportunity to deliver sustainable development projects in a successful way. The previous arguments have included a general way to look at development-oriented managers, who aim to realize sustainable development projects. This can be narrowed down through looking at the influence of a development-oriented manager on team members, as it is essential to encourage collaboration among project team members to build trust (Dzhengiz \& Niesten, 2019), develop their competencies (Mukhopadhyay et al., 2011), and apply creative solutions for sustainable development problems (Dzhengiz \& Niesten, 2019). Consequently, there is a positive relationship between a manager's "development orientation" competency and the achievement of sustainable development projects.

\subsubsection{Achievement Orientation}

Research has supported the existence of an association between "achievement orientation" competency and the successful completion of sustainable development projects (Bruwer et al., 2018; Chung et al., 2016; Dudin et al., 2017; Dzhengiz \& Niesten, 2019; Fulop, 2012; 
Lambrechts et al., 2013; Mukhopadhyay et al., 2011; Remington-Doucette \& Musgrove, 2015; Wiek et al., 2011). Chung, Lo, and Li (2016) have clarified that such achievements include making a positive contribution to the social quality of life, adapting environmental protection measurements, following up what happens to various products after discarding them, encouraging the use of environmentally friendly products, and respecting environmental regulations. Other scholars have argued that the evaluation of managerial competencies and goals' achievement is important to attain better training and development (Dudin et al., 2017). In particular, managers' achievements that are linked to sustainable development cover controlling internal activities as well as managerial conducts (Bruwer et al., 2018); achieving of social, economic and environmental goals (Chung et al., 2016); attaining ambitious missions (Wiek et al., 2011); maintaining continuous progress throughout project phases (Dudin et al., 2017); developing policies to support social, economic, and environmental growth (Chung et al., 2016); acquiring new documentation or potential project plan (Dudin et al., 2017); developing measures for sustainable development (Chung et al., 2016); and delivering project strategic objectives successfully (Dudin et al., 2017). Remington-Doucette and Musgrove (2015) have added that in order for managers to make more valuable sustainable development achievements, managers should understand the dynamics of complex socio-ecological systems; determine and resolve conflicts among stakeholders' values; develop ethics, justice, equity, socio-ecological system integrity; and analyze how the various systems could be advanced in future to improve the environmental, social and economic aspects. Whereas, Chung, Lo, and Li (2016) have related sustainable development achievements to the ability of managers to develop best strategies, follow governmental rules and regulations, and act responsibly towards the environment. Yet, the concept of achievement orientation goes beyond these insights to cover the mitigation of economic risks that threaten the achievement of objectives, as this will ultimately support projects' sustainability (Bruwer et al., 2018). It also involves obligations to prevent pollution, compliance with environmental regulations, and a strong willingness to commit resources to achieve sustainable development (Chung et al., 2016). Here, it is important to understand that minimizing pollution is the main concern when working towards sustainable development, as pollutants have not only negatively affected the quality of life, but also its aspect of long-term sustainable development (Chung et al., 2016). Hereafter, there is a positive relationship between a manager's "development orientation" competency and the achievement of sustainable development projects.

\subsubsection{Motivation}

Similar to knowledge and skills, motivation is important for managers as well as project team members (Remington-Doucette and Musgrove, 2015). Hence, research has highlighted the exitance of a relationship between motivation and the delivery of sustainable development projects (Chung et al., 2016; Dudin et al., 2017; Dzhengiz \& Niesten, 2019; Fulop, 2012; Remington-Doucette \& Musgrove, 2015; Wiek et al., 2011). In general, it is crucial for managers to motivate themselves and others (Wiek et al., 2011). The reason is that managers, who are self-motivated, have the tendency to overcome traditional project contexts and work towards sustainable contexts (Dzhengiz \& Niesten, 2019); acquire more knowledge (Wiek et 
al., 2011); apply innovative ideas that encourage sustainable practices (Dzhengiz \& Niesten, 2019); comply to environmental standards, policies, and regulations (Chung et al., 2016); enhance learning at managerial and teams' level (Dzhengiz \& Niesten, 2019; Remington-Doucette \& Musgrove, 2015); and encourage positive attitudes such as leadership, problem-solving, communication, deliberation, negotiation and collaboration skills (Remington-Doucette \& Musgrove, 2015). This emphasizes the point that a self-motivated manager is key for achieving a sustainable development project successfully. On the other hand, the ability of managers to motivate others adds a great value to sustainable development projects (Dudin et al., 2017; Dzhengiz \& Niesten 2019; Wiek et al., 2011). In justification, motivated managers provide maximum training for project teams, achieve objectives, realize job satisfaction, identify promising managers and team members, use advanced technologies, and improve the quality of goods and services (Dudin et al., 2017). Dzhengiz and Niesten (2019) have added that managers motivate project team members to produce sustainable innovations and ideas, attend more training sessions, engage in resource conservation, participate in environmentally friendly activities, take responsibility for social and environmental matters, engage in environment-oriented accomplishments, apply favorable environmental practices, and accomplish challenging tasks in real-life work environments. Yet, the level of motivation can rise in a way that encourages project team members to compete, achieve goals, improve financial performance, create a positive climate, become responsible, acquire robust competencies, and maintain adhesion (Dudin et al., 2017). This indicates that a well-motivated team can definitely achieve more, as their mindset will entirely be directed towards completing the sustainable development tasks and their energy will be tremendous to reach the final goals. Henceforward, there is a positive relationship between a manager's motivation competency and the achievement of sustainable development projects.

\subsubsection{Teamwork}

Teamwork covers many of the skills necessary to address sustainable development problems such as communication, leadership, planning, organization, delegation, openness to diversity, negotiation skills, empathy, tolerance of differences, and conflict resolution (Remington-Doucette \& Musgrove, 2015). However, several studies have discussed the relationship between teamwork competency and sustainable development projects (Dudin et al., 2017; Dzhengiz \& Niesten, 2019; Fulop, 2012; Lambrechts et al., 2013; Remington-Doucette \& Musgrove, 2015; Wiek et al., 2011). Generally, team members should not only support each other but also evaluate the results of their professional advancement (Dudin et al., 2017). They also should leave traditional methods and become responsible for economic, social, and environmental issues (Dzhengiz \& Niesten, 2019). This can be realized by encouraging managers to build teams and simultaneously encourage collaboration, networking, and developing alliances among project team members (Wiek et al., 2011). Thus, a manager should be able to understand and handle the different aspects that are associated with teams such as weaknesses, strengths, failure, and success (Wiek et al., 2011). They also should be aware of the different methods and techniques that could be followed to gain the maximum possible outcome from team members (Wiek et al., 2011). Furthermore, to increase 
the likelihood of effective teamwork and collaborative experience, it is imperative for managers to maintain a reasonable workload; demonstrate clear objective and expectations; provide appropriate time for teams to complete tasks; give timely feedback during the project period; and acknowledge individual contributions through regular evaluations (Remington-Doucette \& Musgrove, 2015). Nevertheless, it is crucial to acknowledge that team members' expertise should be given strong emphasis, as it is crucial for project team members to complement each other's competencies (Wiek et al., 2011). This indicates that it is not only important to have a manager who encourages teamwork, but also a team that works collaboratively towards achieving sustainable development goals. Accordingly, there is a positive link between a manager's teamwork competency and the achievement of sustainable development projects.

\subsubsection{Innovation}

Managerial competencies have a positive effect on sustainable development, and this is measured by the innovativeness level of managers (Dzhengiz \& Niesten, 2019). Hence, studies have highlighted the existence of a relationship between innovation competency and the accomplishment of sustainable development projects (Bruwer et al., 2018; Chung et al., 2016; Dudin et al., 2017; Dzhengiz \& Niesten, 2019; Fulop, 2012). Innovation is essential to achieve environmental innovations, as it allows managers to modify existing configurations, create better capabilities for energy innovations, and develop better knowledge about strategic innovation (Dzhengiz \& Niesten, 2019). Innovation competency requires managers to have a strong commitment to complete challenging sustainable development activities (Chung et al., 2016). However, a wider adoption of sustainable innovations depends on the ability of managers to communicate these ideas in a way that team members sense them as motivating (Dzhengiz \& Niesten, 2019). Dudin, Vysotskaya, Frolova, Pukhart, and Galkina (2017) have agreed that a good presentation of innovations to others will enhance the outcome of sustainable development. Once the manager delivers all innovation goals, expectations, and directions effectively to team members, they can perform better toward achieving sustainable development. In clarification, when team members understand the new technologies, they will adopt and apply innovative ideas that promote sustainable practices (Dzhengiz \& Niesten, 2019). Team members will also start contributing to sustainable projects' success when they work with a degree of creativity, innovativeness, and autonomy (Dzhengiz \& Niesten, 2019). Moreover, Chung, Lo, and Li (2016) have stated that early compliance with economic, social, and environmental policies can improve sustainable competitiveness especially when a manager acquires innovation competencies. They have also added that market competition is highly affected by productivity and innovation, in turn, this helps to generate benefits to societies (Chung et al., 2016). This implies that innovation competency is not only important to attain sustainable development, but also to survive in the emerging markets. Consequently, there is a positive relationship between a manager's innovation competency and the achievement of sustainable development projects.

\subsubsection{Decision Making}

Decision making competency is strategically derived as decisions to adopt any technology, 
which might be based on external conditions such as competitive pressures of the economy, society, environment, and various governmental regulations (Chung et al., 2016). Thus, many studies have pointed out that decision making is an essential competency for managers who aim to complete sustainable development projects (Bruwer et al., 2018; Chung et al., 2016; Dudin et al., 2017; Dzhengiz \& Niesten, 2019; Fulop, 2012; Lambrechts et al., 2013; Mukhopadhyay et al., 2011; Remington-Doucette \& Musgrove, 2015; Wiek et al., 2011). Managers tend to make more effective decisions when they have a thorough understanding about economic, social and environmental policies and procedures (Mukhopadhyay et al., 2011); financial performances and positions (Bruwer et al., 2018); team members' capabilities and skills (Mukhopadhyay et al., 2011); objective setting, resource allocation, power delegation, and strategic control (Chung et al., 2016). This indicates that decision making is a critical responsibility that entails many important considerations. Further, Wiek, Withycombe, and Redman (2011) have clarified that managers should predict the consequences of their decisions prior to the implementation of sustainable projects in order to protect further generations from wrong plans that could be adopted. They have also elaborated that it is important to identify short-term and long-term consequences of decision making in the context of both direct priorities and long-term concerns (Wiek et al., 2011). In other words, decisions should be studied carefully to avoid undesired outcomes. Still, Bruwer, Coetzee, and Meiring (2018) have mentioned that personal beliefs and values influence the manner in which managers make decisions because their experience might be different. That is why it is better to avoid personal views that do not rely on scientific data or knowledge when making decisions. Managers should also have the ability and willingness to make sustainable, ethical, and responsible decisions; initiate economic, social, and environmental decisions and continuously support relative actions; and hire or upgrade team members based on their values and environmental responsibilities (Dzhengiz \& Niesten, 2019). Yet, Remington-Doucette and Musgrove (2015) have argued that managers need to understand current trends and multiple scenarios of sustainable development; predict effects of today's decisions on the future; and consider alternative responses to a crisis before it occurred, as this would enable rational and informed decision making during the actual crisis (Remington-Doucette \& Musgrove, 2015). Henceforth, there is a positive relationship between a manager's decision-making competency and the achievement of sustainable development projects.

\section{Proposed Model for the Managerial Competencies Required to Achieve Sustainable Development Projects}

Sustainable development is a current necessity that enhances the quality of life (Ciegis et al., 2011; Remington-Doucette \& Musgrove, 2015; Secundo et al., 2020). It can also be defined as "an integrated strategy of sustainable economic development that fosters social inclusion and environmental conservation" (Fukuda-Parr \& Muchhala, 2020, p.104706). Most of the recent projects are directed towards achieving economic growth, social equity, and environmental protection, which are key factors of sustainable development (Secundo et al., 2020; Sobol, 2008; Wiek, et al., 2011). Though, sustainable development projects require managers, who have effective managerial competencies, to expedite the completion of all 


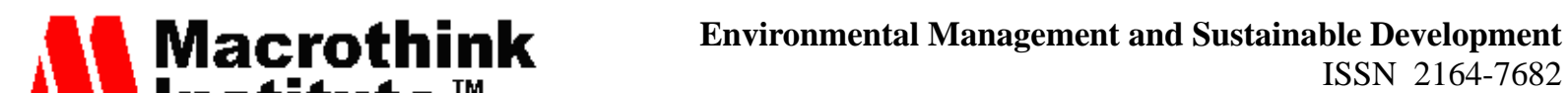 2020, Vol. 9, No. 3}

sustainable development activities and tasks (Bruwer et al., 2018; Dumitrescu, et al., 2014; Dzhengiz \& Niesten, 2019; Mukhopadhyay et al., 2011; Remington-Doucette \& Musgrove, 2015; Wiek et al., 2011). Consequently, this research has proposed a model that demonstrates the existence of a relationship between managers' competencies and the achievement of sustainable development projects as illustrated in Figure 1. This proposed model lists managers' managerial competencies that are most frequently mentioned in the literature to influence sustainable development projects. The model illustrates that communication, leadership, development orientation, achievement orientation, motivation, teamwork, innovation, and decision making are linked to the pillars of sustainable development (economic viability, social inclusion, and environmental protection) (Bruwer et al., 2018; Chung et al., 2016; Dudin et al., 2017; Dumitrescu, et al., 2014; Dzhengiz \& Niesten, 2019; Lambrechts et al., 2013; Mukhopadhyay et al., 2011; Remington-Doucette \& Musgrove, 2015; Sil \& Banerjea, 2011Wiek et al., 2011). Each one of the managerial competencies, demonstrated in Figure 1, has a direct and positive relationship with the three pillars of sustainable development (Bruwer et al., 2018; Chung et al., 2016; Dudin et al., 2017; Dzhengiz \& Niesten, 2019; Fulop, 2012; Mukhopadhyay et al., 2011; Remington-Doucette \& Musgrove, 2015; Sil \& Banerjea, 2011; Wiek et al., 2011). For example, a manager who acquires excellent communication skills has higher opportunity to improve the economy, enhance the society's outcomes, protect the environment from potential harms, while managing a sustainable development project (Bruwer et al., 2018; Dzhengiz \& Niesten, 2019; Mukhopadhyay et al., 2011; Remington-Doucette \& Musgrove, 2015; Wiek et al., 2011). Whereas, a manager who has poor communication skills has less tendency to perform effectively in a sustainable development project nor meet its (economic, social and environmental) targets (Bruwer et al., 2018; Dzhengiz \& Niesten, 2019; Mukhopadhyay et al., 2011; Remington-Doucette \& Musgrove, 2015; Wiek et al., 2011). The same manner applies to the other selected managerial competencies that are leadership, development orientation, achievement orientation, motivation, teamwork, innovation, and decision making. In brief, when these competencies are available and utilized effectively, a sustainable development project can be completed successfully. 
Managers' managerial competencies

for sustainable development Projects

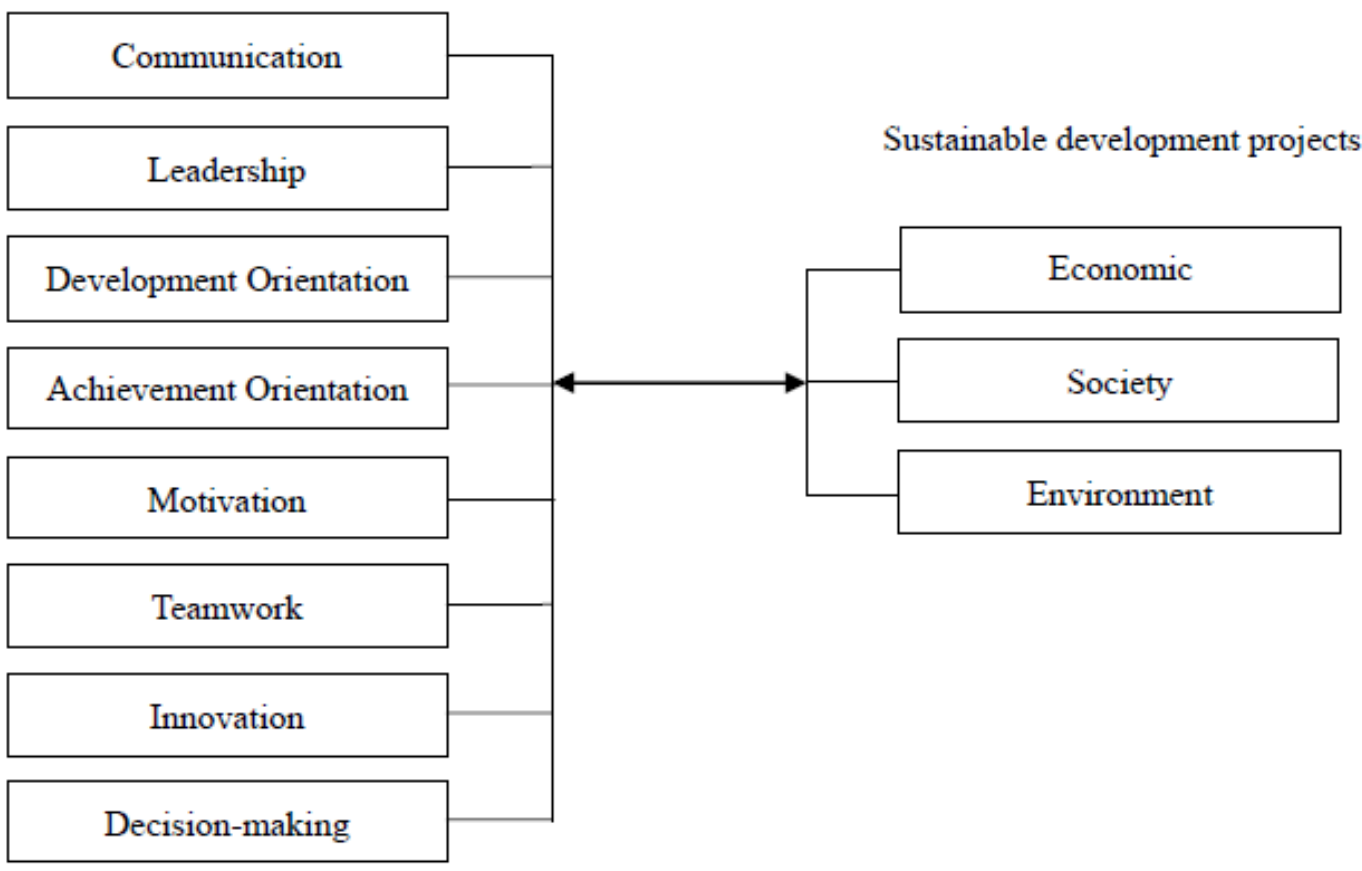

Figure 1. Model of Managers' Managerial Competencies Required to Achieve Sustainable Development Projects

Source: Developed by the Author

\section{Conclusion}

Sustainable development projects can be delivered successfully when managers have the right managerial competencies. This research has pointed out that communication, leadership, development orientation, achievement orientation, motivation, teamwork, innovation, and decision making are critical managerial competencies that are needed to complete sustainable development projects (Bruwer et al., 2018; Chung et al., 2016; Dudin et al., 2017; Dumitrescu, et al., 2014; Dzhengiz \& Niesten, 2019; Lambrechts et al., 2013; Mukhopadhyay et al., 2011; Remington-Doucette \& Musgrove, 2015; Sil \& Banerjea, 2011; Wiek et al., 2011). Given that the appropriate accomplishment of sustainable development projects will lead to economic growth, social equity, and environmental protection (Bruwer et al., 2018; Chung et al., 2016; Dudin et al., 2017; Dzhengiz \& Niesten, 2019; Fulop, 2012; Mukhopadhyay et al., 2011; Remington-Doucette \& Musgrove, 2015; Sil \& Banerjea, 2011; Wiek et al., 2011). Particularly, the model proposed in this study provides a simple presentation for the direct and positive relationship between the found managerial competencies and the main pillars of sustainable development. In other words, there is a direct positive relationship between communication, leadership, development orientation, achievement orientation, motivation, teamwork, innovation, and decision-making competencies and economic viability, social inclusion, and environmental protection. 


\section{Macrothink}

Environmental Management and Sustainable Development

ISSN 2164-7682

2020, Vol. 9, No. 3

Henceforth, managers who do not have these competencies are advised to acquire them through training and daily practice. Whereas, managers who already have these managerial competencies can enhance them for a better outcome, in sustainable development projects.

\section{Acknowledgment}

Many thanks to the previous researchers who have scrutinized on the issues of managerial competencies and sustainable development projects.

\section{References}

Abraham, S., Karns, L., Shaw, K., \& Mena, M. (2001). Managerial competencies and the managerial performance appraisal process. Journal of Management Development, 20(10), 842-852. https://doi.org/10.1108/02621710110410842

Ahsan, K., Ho, M., \& Khan, S. (2013). Recruiting Project Managers: A Comparative Analysis of Competencies and Recruitment Signals from Job Advertisements. Project Management Journal, 44(5), 36-54. https://doi.org/10.1002/pmj.21366

Arditi, D., Gluch, P., \& Holmdahl, M. (2013). Managerial competencies of female and male managers in the Swedish construction industry. Construction Management and Economics, 31(9), 979-990. https://doi.org/10.1080/01446193.2013.828845

Boyatzis, R. E. (1982). The Competent Manager: A Model for Effective Performance. New York: John Wiley. https://doi.org/10.1002/smj.4250040413

Bruwer, J., Coetzee, P., \& Meiring, J. (2018). Can internal control activities and managerial conduct influence business sustainability? A South African SMME perspective. Journal of Small Business and Enterprise Development, 25(5), 710-729.

https://doi.org/10.1108/JSBED-11-2016-0188

$\mathrm{Bu}, \mathrm{N}$. (1994). Red cadres and specialists as modern managers: an empirical assessment of managerial competencies in China. The International Journal of Human Resource Management, 5(2), 357-383. https://doi.org/10.1080/09585199400000022

Bucur, I. (2013). Managerial Core Competencies as Predictors of Managerial Performance, on Different Levels of Management. Procedia - Social and Behavioral Sciences, 78, 365-369. https://doi.org/10.1016/j.sbspro.2013.04.312

Chong, E. (2013). Managerial competencies and career advancement: A comparative study of managers in two countries. Journal of Business Research, 66(3), 345-353.

https://doi.org/10.1016/j.jbusres.2011.08.015

Chung, L., Lo, C., \& Li, P. (2016). The interaction effects of institutional constraints on managerial intentions and sustainable performance. International Journal of Production Economics, 181, 374-383. https://doi.org/10.1016/j.ijpe.2016.01.001

Ciegis, R., Kliucininkas, L., \& Ramanauskiene, J. (2011). Assessment of state and tendencies of sustainable development in Lithuania. Management of Environmental Quality: An International Journal, 22(6), 757-768. https://doi.org/10.1108/14777831111170858 


\section{Macrothink}

Environmental Management and Sustainable Development

ISSN 2164-7682

2020, Vol. 9, No. 3

Cockerill, T., Hunt, J., \& Schroder, H. (1995). Managerial Competencies: Fact or Fiction?. Business Strategy Review, 6(3), 1-12. https://doi.org/10.1111/j.1467-8616.1995.tb00095.x

Dudin, M., Vysotskaya, N., Frolova, E., Pukhart, A., \& Galkina, M. (2017). Improving professional competence of the staff as a strategic factor for sustainable development of companies. Journal of Business \& Retail Management Research, 12(01).

https://doi.org/10.24052/JBRMR/V12IS01/IPCOTSAASFFSDOC

Dumitrescu, C., Drăghicescu, L., Olteanu, R., \& Suduc, A. (2014). Key Competences for Sustainable Development - Aspects Related with SUSTAIN Project Activity. Procedia Social and Behavioral Sciences, 141, 1101-1105.

https://doi.org/10.1016/j.sbspro.2014.05.185

Dzhengiz, T., \& Niesten, E. (2019). Competences for Environmental Sustainability: A Systematic Review on the Impact of Absorptive Capacity and Capabilities. Journal of Business Ethics, 162(4), 881-906. https://doi.org/10.1007/s10551-019-04360-z

Fanelli, S., Lanza, G., Enna, C., \& Zangrandi, A. (2020). Managerial competences in public organisations: the healthcare professionals' perspective. BMC Health Services Research, 20(1), 1-9. https://doi.org/10.1186/s12913-020-05179-5

Fukuda-Parr, S., \& Muchhala, B. (2020). The Southern origins of sustainable development goals: Ideas, actors, aspirations. World Development, 126, 104706.

https://doi.org/10.1016/j.worlddev.2019.104706

Isidro-Filho, A., Guimarães, T., Perin, M., \& Leung, R. (2013). Workplace learning strategies and professional competencies in innovation contexts in Brazilian hospitals. BAR - Brazilian Administration Review, 10(2), 121-134. https://doi.org/10.1590/S1807-76922013000200002

Lambrechts, W., Mulà, I., Ceulemans, K., Molderez, I., \& Gaeremynck, V. (2013). The integration of competences for sustainable development in higher education: an analysis of bachelor programs in management. Journal of Cleaner Production, 48, 65-73.

http://dx.doi.org/10.1016/j.jclepro.2011.12.034

Lampel, J. (2001). The core competencies of effective project execution. International Journal of Project Management, 19(8), 471-483.

https://doi.org/10.1016/S0263-7863(01)00042-4

Long, C., \& Ismail, W. (2011). An analysis of the relationship between HR professionals' competencies and firms' performance in Malaysia. The International Journal of Human Resource Management, 22(5), 1054-1068. https://doi.org/10.1080/09585192.2011.556779

Long, C., Ismail, W., \& Amin, S. (2013). The role of change agent as mediator in the relationship between HR competencies and organizational performance. The International Journal of Human Resource Management, 24(10), 2019-2033.

https://doi.org/10.1080/09585192.2012.725080

Liikamaa, K. (2015). Developing a Project Manager's Competencies: A Collective View of the Most Important Competencies. Procedia Manufacturing, 3, 681-687. 
https://doi.org/10.1016/j.promfg.2015.07.305

McGregor, J., \& Tweed, D. (2001). Gender and managerial competence: support for theories of androgyny?. Women in Management Review, 16(6), 279-287.

https://doi.org/10.1108/09649420110401540

Meng, Q., \& Li, G. (2001). A theoretical discussion on types and measurement of sustainable development. Chinese Geographical Science, 11(3), 201-210.

https://doi.org/10.1007/s11769-001-0016-2

Mukhopadhyay, K., Sil, J., \& Banerjea, N. (2011). A Competency Based Management System for Sustainable Development by Innovative Organizations. Vision: The Journal of Business Perspective, 15(2), 153-162. https://doi.org/10.1177/097226291101500206

Raišienè, A. (2014). Leadership and Managerial Competences in a Contemporary Organization from the Standpoint of Business Executives. Economics \& Sociology, 7(3), 179-193. https://doi.org/10.14254/2071-789X.2014/7-3/14

Remington-Doucette, S., \& Musgrove, S. (2015). Variation in sustainability competency development according to age, gender, and disciplinary affiliation: Implications for teaching practice and overall program structure. International Journal of Sustainability in Higher Education, 16(4), 537-575. https://doi.org/10.1108/IJSHE-01-2013-0005

Sachs, J. (2012). From Millennium Development Goals to Sustainable Development Goals. The Lancet, 379(9832), 2206-2211. https://doi.org/10.1016/S0140-6736(12)60685-0

Secundo, G., Ndou, V., Vecchio, P., \& De Pascale, G. (2020). Sustainable development, intellectual capital and technology policies: A structured literature review and future research agenda. Technological Forecasting and Social Change, 153, 119917.

https://doi.org/10.1016/j.techfore.2020.119917

Shaikh, A., Bisschoff, C., \& Botha, C. (2017). A Theoretical Model to Measure Managerial and Leadership Competence of Business School Managers. Journal of Economics and Behavioral Studies, 9(6), 149-165. https://doi.org/10.22610/jebs.v9i6(J).2012

Sobol, A. (2008). Governance barriers to local sustainable development in Poland. Management of Environmental Quality: An International Journal, 19(2), 194-203. https://doi.org/10.1108/14777830810856573

Wadongo, B., Kambona, O., \& Odhuno, E. (2011). Emerging critical generic managerial competencies. African Journal of Economic and Management Studies, 2(1), 56-71. https://doi.org/10.1108/20400701111110777

Watson, S., McCracken, M., \& Hughes, M. (2004). Scottish visitor attractions: managerial competence requirements. Journal of European Industrial Training, 28(1), 39-66.

https://doi.org/10.1108/03090590410513884

Wickramasinghe, V., \& De Zoyza, N. (2011). Managerial competency requirements that enhance organisational competences: a study of a Sri Lankan telecom organisation. The 


\section{Macrothink \\ Environmental Management and Sustainable Development \\ ISSN 2164-7682 \\ 2020, Vol. 9, No. 3}

International Journal of Human Resource Management, 22(14), 2981-3000.

https://doi.org/10.1080/09585192.2011.588038

Wiek, A., Withycombe, L., \& Redman, C. (2011). Key competencies in sustainability: a reference framework for academic program development. Sustainability Science, 6(2), 203-218. https://doi.org/10.1007/s11625-011-0132-6

\section{Copyright Disclaimer}

Copyright for this article is retained by the author(s), with first publication rights granted to the journal.

This is an open-access article distributed under the terms and conditions of the Creative Commons Attribution license (http://creativecommons.org/licenses/by/4.0/). 